\title{
A Study on the Relationship between Sexuality, Spirituality and Well-Being amongst adults in Mumbai
}

\author{
Zankhana Joshi ${ }^{1}$ \\ ${ }^{1}$ Post Graduate Student, Department of Psychology, Maniben Nanavati Women's College, Mumbai \\ E-mail-zankhanajoshi@gmail.com
}

\begin{abstract}
A study showing a positive association between Sexuality, Spirituality and well-being have been very rare in the past. Attempts have been made to understand and establish this relationship better, as it can have implications on an individual's wellbeing. Sexuality has been viewed pejoratively in the past. The study hopes to open the discussion and bring forward sexuality in a positive psychology framework by establishing positive association between an Individual's satisfaction with sex and his/her overall well being. One hundred ninety-one adults between ages 25-45 from the region of Mumbai were the participants. Data was collected using online surveys (Google Docs). Questions relating to Eudaimonic well-being, Hedonic well-being, spirituality and sexuality were asked in the questionnaire. There exists a positive relationship amongst Sexuality, Spirituality and well-being. The findings from the research suggested that (1) Sexual satisfaction has a generally positive association with hedonic wellbeing; (2) Sexual satisfaction has a generally positive association with eudaimonic wellbeing; (3) Spirituality has a generally positive association with hedonic wellbeing; (4) Spirituality has a generally positive association with eudaimonic wellbeing; (5) Sexual satisfaction has a generally positive association with spirituality. We can conclude that if an individual is sexually satisfied his overall well-being (Hedonic and Eudaimonic) will also be satisfactory. Also, if a person is spiritually more inclined it is likely that his/her overall well-being (Hedonic and Eudaimonic) will also be higher, and lastly, if a person is sexually satisfied then he/she will be more spiritual.
\end{abstract}

Key words: Sexual satisfaction, Hedonic well-being, Eudaimonic well-being, spirituality.

\section{INTRODUCTION}

Sexuality is often associated with the dangers of sexual activities such as sexually transmitted diseases, unintended pregnancy and sexual crimes thus threatening the political, social, and spiritual systems. Authorities have tried to curb sexual instincts through preaching the virtues of social control, chastity, and circumspection. This suppression over centuries has led to asocial manifestations which are later attributed to sexualities [1]. (Arakawa, D.R et al, 2012).

Spirituality can be defined as the internal experience of the individual and a process of transformation, but in a context separate from organized religious institutions [2]. Spirituality is also now associated with mental health, managing substance abuse, marital functioning, parenting, and coping. It has been suggested that spirituality also leads to finding purpose and meaning in life. Relationship between 
Spirituality and sexuality can be seen in the work of Carl Jung, who believed that the opposite unconscious sexual element (anima/animus) can fuel the spiritual journey toward wholeness. Authors have called for a "reconciliation" of these domains [3]. Psychologists have expressed that spirituality and sexuality share a commonality in that both have origins in the pervading sense of human incompleteness and the desire to be whole [4].

Well-being refers to optimal psychological functioning and experience [5]. The current theories of well-being are atuned to the notion of hedonism - striving for maximisation of pleasure (positive affect) and minimisation of pain (negative affect). This hedonic view can be traced to Aristippus, who believed that the goal of life is to experience maximum pleasure. Recently, the idea of eudaimonic well-being has arisen. Aristotle was the originator of the concept of eudaimonia (from daimon - true nature). He deemed happiness to be a vulgar idea, stressing that not all desires are worth pursuing as, even though some of them may yield pleasure, they would not produce wellness. Aristotle thought that true happiness is found by leading a virtuous life and doing what is worth doing. He argued that realizing human potential is the ultimate human goal [6].

In a study on sexuality and spirituality using a phenomonological inquiry of eleven midlife women, it was concluded that results indicated that spirituality and sexuality were connected in a cyclical pattern for the participants with positive effect [7]. Another study documented that relationship satisfaction and sexual assertiveness increased the ability to predict sexual satisfaction in women while controlling for age, relationship status, and length of relationship [8].

A review paper that examined papers published between 1960 and 2010 found that relatively speaking there are more negative articles than neutral or positive articles on this theme [1]. More specifically, these results indicate that journals tend to publish less research focusing on the positive aspects of sexuality than articles focusing on the problems, dangers, and negative aspects of sexuality. Studies in adolescents have indicated that sexually experienced and on-time students reported higher wellbeing than sexually inexperienced or late onset students [9]. In yet another student survey, researchers found that $75 \%$ of all students surveyed thought spirituality and sexuality were related. $76 \%$ percent of both general population and ministry students believe that spirituality and sexuality are related [10].

A study showing a positive association between Sexuality, Spirituality and well-being have been very rare in the past. Attempts have been made to understand and establish this relationship better, as it can have implications on an individual's wellbeing. Sexuality has been viewed pejoratively in the past. The study hopes to open the discussion and bring forward sexuality in a positive psychology framework by establishing positive association between an individual's satisfaction with sex and his/her overall well being. Sexuality and Spirituality are considered to be distinct domains; the study purports to establish that both sexuality and spirituality are different paths that lead to human completeness [11].

\section{METHODOLOGY}

The study focuses on the Relationship between Sexuality, spirituality and well-being (hedonic and Eudaimonic) amongst adults in Mumbai. The relationship between the four variables were studied using a predictive correlational design. A purposive, snowball sampling method was used to get responses from 220 participants using an online survey on a no-name basis. Participants were aged between 
25-45 years, living in Mumbai, India. 29 surveys were returned incomplete or with substantial amount of missing data, and were thus excluded from the sample. So the remaining were 191 participants (51\% Female and 49\% Male). The participants were largely matched for education qualification and socio-economic background.

The research study consisted of five variables:

Sexual satisfaction - It is a global evaluation by the person of his or her sex life. It is a subjective judgment rather than a judgment based on some externally imposed objective standard

Spirituality - Spirituality is commonly associated with an existential search for meaning and purpose. Spirituality is defined by persons' subjective experiences ; distinguished from religion

Well being - Positive well-being refers to optimal psychological functioning and experience. Hedonic and eudaimonic well-being have been established as related, yet unique aspects of thriving that distinguish between a happy and a meaningful life.

Hedonism - considers well-being as consisting of positive cognitive evaluations and affective states, such as pleasure, happiness, and life satisfaction. The attempt to maximize pleasure and minimize pain

Eudaimonism - posits that well-being lies in the actualization of human potentials and successful coping with objective life challenges, such as developing and maintaining positive relations with others, self-acceptance, control over one's environment, autonomy, purpose in life, and growth.

\section{Hypotheses used in the study}

$\mathrm{H} 1$ : Sexual satisfaction has a generally positive association with hedonic wellbeing

$\mathrm{H} 2$ : Sexual satisfaction has a generally positive association with Eudaimonic wellbeing

H3: Spirituality has a generally positive association with hedonic wellbeing

$\mathrm{H} 4$ : Spirituality has a generally positive association with Eudaimonic wellbeing

H5: Sexual satisfaction has a generally positive association with spirituality

\section{Scales Used}

- Sexual satisfaction was assessed with the Global Measure of Sexual Satisfaction (GMSEX), developed by Lawrence and Byers in1998; Respondents rate on five 7point dimensions. It has a high internal consistency $(.90-.96)$ and Test-retest reliabilities (0.84 at 2 weeks, 0.78 at 3 months) [12].

- Spirituality was assessed with the Spirituality Assessment Scale (SAS), developed by Howden in 1992; a 28-item Likert scale; measures spiritual attributes in four areas Purpose and meaning in Life, Transcendence, Inner Resources, and Unifying Interconnectedness. It has a high internal consistency overall and good construct validity [13].

- Hedonic wellbeing was assessed with The Satisfaction with Life Scale (SWLS), developed by Diener, Emmons, Larson and Griffins in 1985; a 5 item Likert scale. It has a strong internal consistency (Cronbach's alpha 0.83) and high test-retest stability; good construct and discriminant validity [14].

- Eudaimonic wellbeing was assessed with the Scales of Psychological Well-Being (SPWB), developed by Ryff's and Keyes in 1995; an 18-item Likert Scales assesses six domains: self-acceptance, autonomy, purpose in life, relations with others, environmental mastery, and personal growth. It also provides a total score of positive psychological functioning. It has a high internal consistency 
(Cronbach's alpha was 0.79 ), test-retest stability, and construct validity among adults [15].

\section{Statistical Analysis}

The variables were studied using a predictive correlation design. The tools used did not give a cut-off score, hence these factors could not be manipulated in an IV/DV format, and thus the study used a correlational design. Once a strong positive correlation was obtained a multiple regression analysis was done to predict the value of one variable based on the value of the other variables. The inferential statistical measure used to analyze the relationship between two variables was Pearson's Product Moment $\mathrm{R}$ (correlation). A multiple regression was computed to assess the predictive value of one variable on the three other variables. It was expected that there would be a strongest positive relation between Spirituality and Eudaimonic wellbeing; a strong positive relations between Spirituality and Hedonic wellbeing. However since Sexuality is viewed pejoratively the relationship between Sexual Satisfaction and Spirituality as well as Eudaimonic and Hedonic Wellbeing was expected to be positive, but weak.

\section{RESULTS}

The mean scores obtained on various scales are described below.

Table 1: Calculated Means (M) and Standard deviation (SD) for the respective variables

\begin{tabular}{|l|c|c|}
\hline Variables & Mean (M) & Standard Deviation (SD) \\
\hline Sexual satisfaction & 22.0 & 10.2 \\
\hline Eudaimonic Well-being & 75.2 & 16.5 \\
\hline Hedonic Well-being & 19.9 & 7.8 \\
\hline Spirituality & 112.2 & 36.1 \\
\hline
\end{tabular}

There is a positive correlation between Sexual Satisfaction and Hedonic well-being, $r(189)=0.64, p<0.0001$. There is a positive correlation between Sexual Satisfaction and Eudaimonic well-being, $r(189)=0.66, p<0.001$. There is a positive correlation between Sexual satisfaction and Spirituality, $r(189)=0.70, p<0.0001$. There is a positive correlation between Hedonic well-being and Spirituality $r(189)=0.77$, $\mathrm{p}<0.001$. And finally, there is a positive correlation between Eudaimonic well-being and Spirituality $r(189)=0.85, p<0.001$. The P-value is $<0.0001$ for the correlation between all the variables and hence the all the five hypotheses are accepted.

Table 2: The Pearson's Product Moment Correlation

\begin{tabular}{|l|c|c|c|c|}
\hline & $\begin{array}{l}\text { Sexual } \\
\text { Satisfaction }\end{array}$ & $\begin{array}{l}\text { Eudaimonic } \\
\text { Well-being }\end{array}$ & $\begin{array}{l}\text { Hedonic Well- } \\
\text { being }\end{array}$ & Spirituality \\
\hline $\begin{array}{l}\text { Sexual } \\
\text { Satisfaction }\end{array}$ & 1 & & & \\
\hline $\begin{array}{l}\text { Eudaimonic } \\
\text { Well-being }\end{array}$ & $0.66^{* *}$ & 1 & 1 & \\
\hline $\begin{array}{l}\text { Hedonic } \\
\text { Well-being }\end{array}$ & $0.64^{* *}$ & $0.77^{* *}$ & & \\
\hline Spirituality & $0.70^{* *}$ & $0.85^{* *}$ & $0.77^{* *}$ & 1 \\
\hline
\end{tabular}


Therefore, the results of the research study support all the null hypotheses. The association between Sexual satisfaction and hedonic wellbeing was expected to be positive given that they both would seek pleasure. The results support the hypothesis. The association between Sexual Satisfaction and Eudaimonic wellbeing was expected to be a weak positive. Sexuality has been viewed pejoratively as only a pleasure seeking activity, whereas Eudaimonic wellbeing is about realizing human potential. However, the results indicate that there was a significant positive association between the two variables. The association between Spirituality and Hedonic wellbeing was expected to be positive. as both seek to make the subjective evaluation of life satisfying. The results also indicate a strong positive association between these two variables. The association between Spirituality and Eudaimonic wellbeing was expected to be positive given that they both would seek internal actualization and finding meaning and purpose. The results support the hypothesis.

Popular beliefs would indicate that the relationship between Sexual Satisfaction and Spirituality would be negative or at best a weak positive, since sexual satisfaction aims to seek pleasure, and spirituality (especially religions) would seek God and stay away from pleasure seeking activities. However, the correlation was a strong positive. The Multiple Regression was computed to assess the predictive value of $(Y)$ on the three other variables (X1), (X2), and (X3), with the 4 variables being sexual satisfaction, Eudaimonic Well-being, Hedonic Well-being, and Spirituality. The table also shows the adjusted R square, significance of F, Coefficients, Standard Error, and P-value. The adjusted $R$ square is 0.51 . The significance of $F$ is $<0.01$. The standard errors are not very high and the P-values are not too high indicating that the coefficients seem inline.

As indicated by the results of the study, Individuals usually experiences Sexual Satisfaction when they are satisfied with life in general and enjoy a healthy and balanced life. Satisfaction does not only depend on the frequency of sexual intimacy but also the quality.

Table 3: Predicting Sexual Satisfaction

\begin{tabular}{|l|l|}
\hline Adjusted R Square & 0.51 \\
\hline Significance F & $<0.01$ \\
\hline Coefficients & \\
\hline Eudaimonic Well-being & 0.11 \\
\hline Hedonic Well-being & 0.27 \\
\hline Spirituality & 0.11 \\
\hline Standard Error & \\
\hline Eudaimonic Well-being & 0.06 \\
\hline Hedonic Well-being & 0.11 \\
\hline Spirituality & 0.03 \\
\hline P-value & \\
\hline Eudaimonic Well-being & 0.09 \\
\hline Hedonic Well-being & 0.02 \\
\hline Spirituality & 0.00 \\
\hline
\end{tabular}


Table 4: Predicting Spirituality

\begin{tabular}{|l|l|}
\hline Adjusted R Square & 0.77 \\
\hline Significance F & 0.0000 \\
\hline Coefficients & \\
\hline Sexual Satisfaction & 0.67 \\
\hline Eudaimonic Well-being & 1.18 \\
\hline Hedonic Well-being & 1.10 \\
\hline Standard Error & \\
\hline Sexual Satisfaction & 0.17 \\
\hline Eudaimonic Well-being & 0.13 \\
\hline Hedonic Well-being & 0.26 \\
\hline P-value & \\
\hline Sexual Satisfaction & 0.00 \\
\hline Eudaimonic Well-being & 0.00 \\
\hline Hedonic Well-being & 0.00 \\
\hline
\end{tabular}

Table 5: Predicting Hedonic Well-being

\begin{tabular}{|l|l|}
\hline Adjusted R Square & 0.65 \\
\hline Significance F & 0.0000 \\
\hline Coefficients & \\
\hline Spirituality & 0.08 \\
\hline Sexual Satisfaction & 0.11 \\
\hline Eudaimonic Well-being & 0.17 \\
\hline Standard Error & \\
\hline Spirituality & 0.02 \\
\hline Sexual Satisfaction & 0.05 \\
\hline Eudaimonic Well-being & 0.04 \\
\hline P-value & \\
\hline Spirituality & 0.00 \\
\hline Sexual Satisfaction & 0.02 \\
\hline Eudaimonic Well-being & 0.00 \\
\hline
\end{tabular}

Table 6: Predicting Eudaimonic Well-being

\begin{tabular}{|l|l|}
\hline Adjusted R Square & 0.75 \\
\hline Significance F & 0.0000 \\
\hline Coefficients & \\
\hline Hedonic Well-being & 0.55 \\
\hline Spirituality & 0.27 \\
\hline Sexual Satisfaction & 0.14 \\
\hline Standard Error & \\
\hline Hedonic Well-being & 0.12 \\
\hline Spirituality & 0.03 \\
\hline Sexual Satisfaction & 0.08 \\
\hline P-value & \\
\hline Hedonic Well-being & 0.00 \\
\hline Spirituality & 0.00 \\
\hline Sexual Satisfaction & 0.09 \\
\hline
\end{tabular}




\section{DISCUSSION}

In the past, studies linking Sexuality with Spirituality and Wellbeing have been rare. Sexuality was viewed suspiciously as the root cause of neuroses, anxiety and perversions. Based on the results of the study we can conclude that if an individual is sexually satisfied his overall well-being (Hedonic and Eudaimonic) will also be satisfactory. Also, if a person is spiritually more inclined it is likely that his/her overall well-being (Hedonic and Eudaimonic) will also be higher, and lastly, if a person is sexually satisfied then he/she it likely to be more spiritual.The study hypothesized a positive relation between Spirituality and Sexual Satisfaction, as they both seek wholeness. However, the strength of the correlation was above expectation and substantiates the hypothesis and thereby the research significantly. Thus showing that a healthy sexuality is an integral part of an individual's Wellbeing and Spirituality [16].

An adult's sexuality has several components gender identity, orientation, intention, desire, arousal, orgasm, and emotional satisfaction. This study focuses only on one aspect of 'sexual satisfaction'. Since Sexual Satisfaction is a very private matter participant response may not have been honest despite conducting the survey on a no-name basis. Since this is a correlational study, it cannot prove a causal relationship; hence we cannot say with certainty that high well-being will lead to higher sexually satisfaction or vice-versa; or higher spirituality will lead to higher sexual satisfaction. The study did not separate groups by gender, ethnicity, or age, and thus does not reflect any intergroup or intragroup differences that may exist [17].

The finding of this study suggests various implications for educators, mental health counselors, and adults. Since the study establish a strong and positive correlation between sexuality and spirituality as well as wellbeing. One can be certain that any improvement in one of the areas may have a positive implication on the other area. Parents and Educators can demystify sex and share the benefits of healthy sexuality with adolescents and young adults which, may help avoid perversions and obsessions. Sexual satisfaction could be explored from the first encounter which in turn could enhance their wellbeing [18]. Sexual Disorders like Gender Identity Disorders could establish the link between the associated anxieties and its implications on their wellbeing and Spirituality. It can also explain the possible lower wellbeing and spirituality of closeted homosexuals who are not allowed to freely express and experience their sexual preferences. For patients suffering from Sexual Dysfunction, the study can help to educate, understand and improve the well-being of the group. Patients displaying symptoms of low sexual drive (depression and anxiety) could explore the possibility of improving their sexual satisfaction which in turn could improve their wellbeing and spirituality and help them cope better [19]. Sex is a key part of marriage that is often less than fulfilling and satisfactory. Especially in India where sexual compatible is not known prior to marriage Higher expectations for sex and marriage require new insights and education is needed to make it fulfilling. The understanding can help enhance and deepen the sexual and spiritual experience and foster wellbeing [20]. 


\section{REFERENCES}

1. Arakawa DR, Corey E, Flanders EH, Ronald, H. Positive Psychology: What Impact has it had on Sex Research Publication. Trends In Sexuality \& Culture: An Interdisciplinary Quarterly 2013;17(2):305-20.

2. Harrocks R. Freud Revisited: Psychoanalytical themes in a post modern age. UK: Palgrave Macmillan ; 2001.

3. Jung CG. Modern man in search of a soul. New York: Harcourt Press \& World; 1993.

4. Csikszentmihalyi M. Finding flow: The psychology of engagement with everyday life. New York: Basic Books ; 1997.

5. Baker DC. Studies of the inner life: The impact of spirituality on quality of life. Quality of Life Research 2003;12:51-7.

6. Zullig KJ, Ward RM, Horn T. The association between perceived spirituality, religiosity, and life satisfaction: The mediating role of self-rated health. Social Indicators Research $2006 ; 79(2): 255-74$.

7. Davidson JK, Darling CA, Norton L. Religiosity and the sexuality of women: Sexual behavior and sexual satisfaction revisited. The Journal of Sex Research 1995;32(3):235-9.

8. Marschke E, Preziosi R, Harrington WJ. How sales personnel view the relationship between job satisfaction and spirituality in the workplace. Journal of Organizational Culture, Communication and Conflict $2011 ; 15(2): 71-110$.

9. Montesi JL, Conner BT, Gordon EA, Fauber RL, Kim KH, Heimberg RG. On the relationship among social anxiety, intimacy, sexual communication, and sexual satisfaction in young couples. Archives of Sexual Behavior 2013;42(1):81-91.

10. Vrangalova Z, Savin-Williams R. Adolescent sexuality and positive well-being: A groupnorms approach. Journal of Youth and Adolescence 2011;40(8):931-44.

11. Chavez-Garcia S, Helminiak DA. Sexuality and spirituality: Friends, not foes. Journal of Pastoral Care 1985;39(2):151-63.

12. Byers ES. Relationship satisfaction and sexual satisfaction: A longitudinal study of individuals in long term relationships. J Sex Research 2005;42(2):113-8.

13. Howden J. Development and psychometric characteristics of the Spirituality Assessment Scale ; 1992.

14. Diener E, Diener C. Most people are happy. Psychol Science 1995;7(3):181-5.

15. Keyes CLM. Social well being. Soc Psychol Quart 1998;3:121-40.

16. Bancroft J. Human Sexuality and Its Problems. Edinburgh: Churchill Livingstone ; 1989.

17. Clark SE, Clark JK. Spirituality and sexuality: Compatible components for optimal health. The Journal of School Health 2004;74(1):30-6.

18. Helminiak DA. Sexuality and spirituality: A humanist account. Pastoral Psychology 1998;47(2):119-26.

19. McCabe MP, Cummins RA. Sexuality and quality of life among young people. Adolescence 1998;33(132):761-73.

20. Murray J. Sexuality and spirituality: The intersection of medieval theology and medicine. Fides et Historia 1991;23:20-36.

Acknowledgements - Nil

Conflict of Interest - Nil

Funding - Nil. 